\title{
Smart City as Urban Innovation: A Case of Riyadh North-West District
}

\author{
Abdulaziz N. Aldusari ${ }^{1}$ \\ ${ }^{1}$ King Saud University (KSU), Riyadh, Saudi Arabia \\ Correspondence: Abdulaziz N. Aldusari, King Saud University (KSU), Riyadh, Saudi Arabia. Tel: \\ 966-50-548-9985. E-mail: Adawsari@mohe.gov.sa
}

Received: April 30, 2015 Accepted: July 23, 2015 Online Published: September 29, 2015

doi:10.5539/jsd.v8n8p270 URL: http://dx.doi.org/10.5539/jsd.v8n8p270

\begin{abstract}
Saudi Arabia has recently adopted and implemented an enduring strategy of development that shifts its focal point towards the formulation of knowledge based society. In the same context, KSU (King Saud University), in Riyadh has initiated the project of the Riyadh Techno Valley (RTV), within its campus. The projects aims to strengthen its efforts, in order to develop knowledge based society in Saudi Arabia. KSU as a core of the North-West district of Riyadh had an initiative by adopting a comprehensive idea of Riyadh Knowledge Corridor (RKC) in Prince Turki Alawal Road area. KSU has started to take an active role in setting up new Riyadh's Smart City node (Smart Riyadh - NWD). The focal point of it is the Riyadh Techno Valley (RTV) project, which is expected to play a central anchored role with other developments in this district such as King Abdul Aziz City for Science and Technology, information technology and communication complex, Saudi Standards, King-Abdulaziz-and-his-Companions-foundation-for-Giftedness-and-Creativity, and king Abdullah financial center. This research study will assesses Riyadh Techno Valley, which will help in reflecting several issues and principals towards the evolution of the North-West district in Riyadh as Smart city.
\end{abstract}

Keywords: urban planning, Sustainable development, Riyadh Techno Valley

\section{Introduction}

\subsection{Evolving of a Smart Riyadh North-West District}

The King Saud University (KSU) is one of the most prominent center of the North-West district of Riyadh. KSU has taken a commendable step by adopting the concept of RKC (Riyadh Knowledge Corridor), in the area of Prince Turki Alawal road (Al-Filali \& Gallarotti, 2012, p. 19). It has been assessed that KSU aims to set-up and develop new Riyadh's Smart City and the focal point of the project is to develop the project of Riyadh Techno Valley (RTV). It is expected that the project will play an inevitable role in fostering other developments, like King Abdul Aziz city for science and technology. It is significant to bring into the notice that this new urban center (Smart Riyadh - NWD) will be added to the four urban centers that was already been suggested by the strategic plan of Al-Riyadh Development Authority (ADA).

The strategic plan is illustrated in figure 1. In addition to this, the strategic plan of Riyadh can also be analyzed from figure 2. It is quite evident from the diagram that the plan possesses two new residential satellites on the north (sultana) and the other one is on the east (Alwasee). It is also observed that the newly proposed urban center, i.e., the Smart Riyadh North - West district (Smart Riyadh - NWD), will also have a residential community. It is due to the fact that the main concept of this center is to ensure a new urbanism development with a mix land use. 


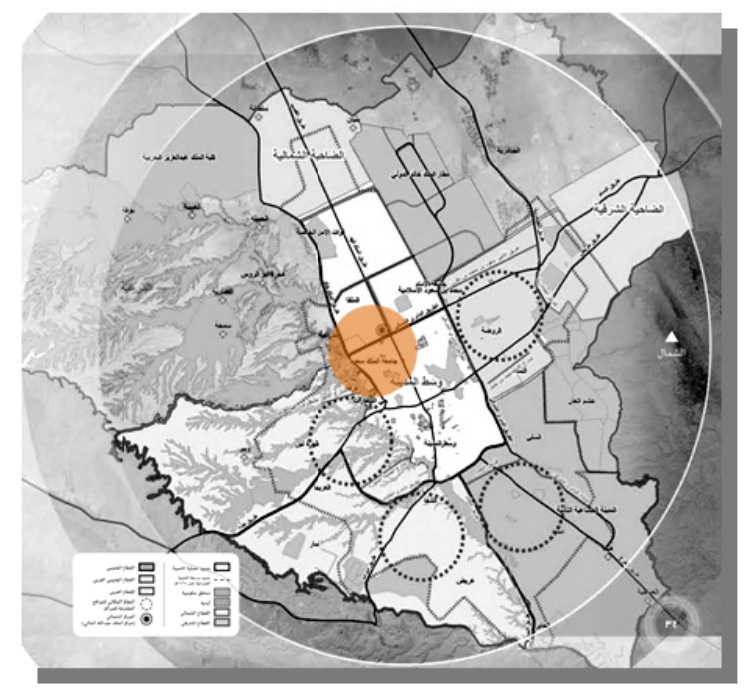

Figure 1. Riyadh strategic plan showing the new urban center

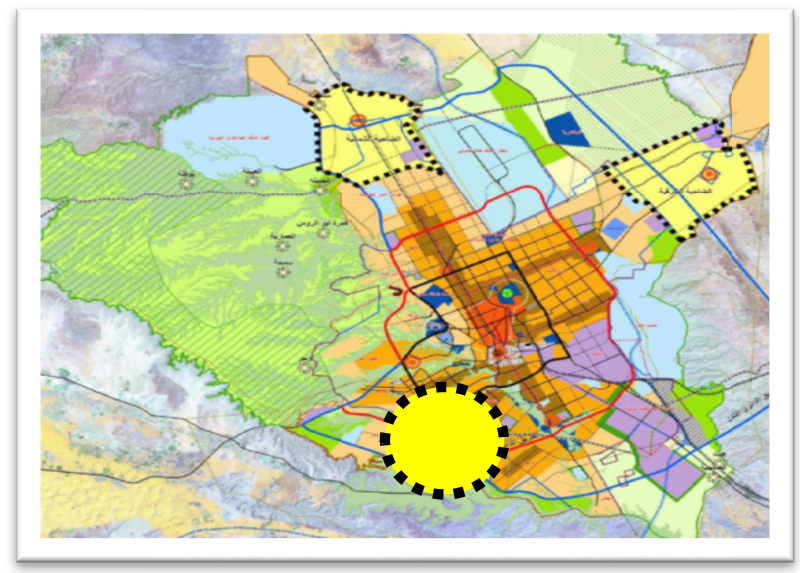

Figure 2. Strategic Plan for Riyadh with two Satellite, i.e., North: Sultana, East: Alwasee and Smart Riyadh NWD

\subsection{Riyadh Knowledge Corridor (RKC) Core Area for Smart Riyadh-NWD}

The project of RKC (Riyadh Knowledge Corridor) is found to be the contemporary tool, which is planned around an interlinked group of innovation outlets and pioneering knowledge. The connection of these outlets is provided by the objectives and vision of developing a knowledge-based society. In view of the fact that, the city of Riyadh incorporates a wide range of knowledge and economic entities, which are able to effectively contribute in developing such societies, which are proposed by KSU. It has been observed that the proposed project of KSU, i.e., Riyadh Knowledge Corridor Program, is the greatest initiative towards the development of strong link amid knowledge, intellectual, economic, research, and educational entities. Appendix C (figure 3) shows the map of Riyadh Knowledge Corridor Program. 


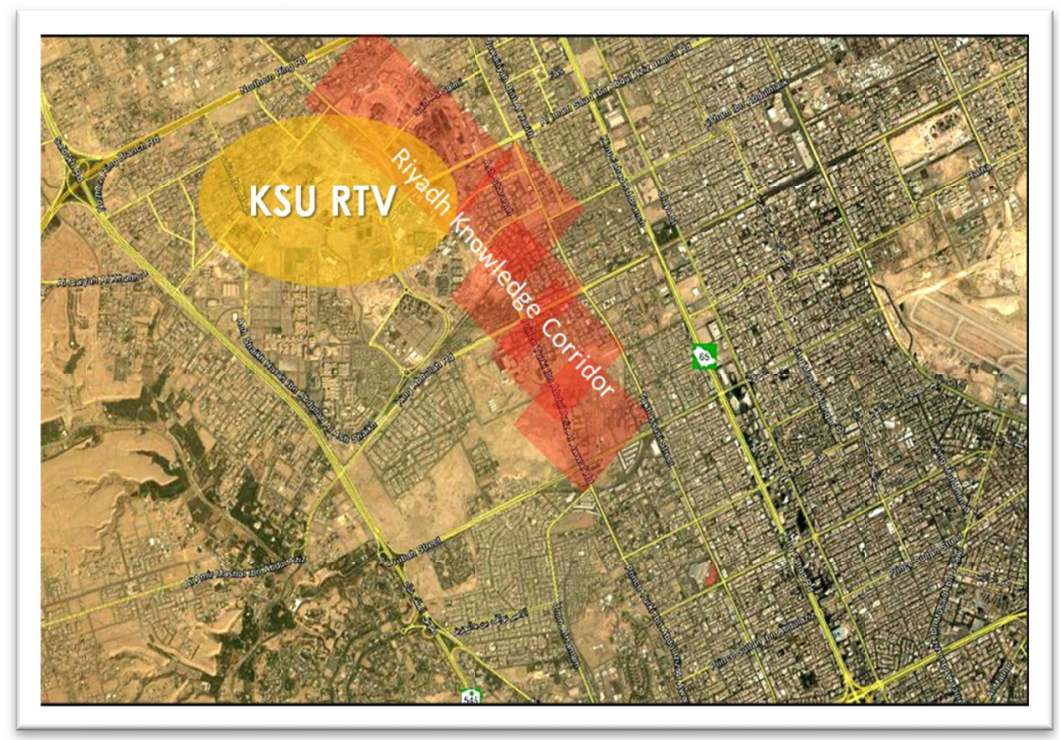

Figure 3. Riyadh Knowledge Corridor (RKC) in the North - West District of Riyadh

It has been established that one of the major objectives behind this project is to improve and enhance the communication and interaction among all of these entities, in a smart and convenient manner. The objectives to be achieved for Riyadh Knowledge Corridor (RKC) include:

- Creation of a smart zone of attraction with high tech new urbanization for different sections of society in Riyadh;

- Fostering adequate and beneficial partnerships among the sources of innovation and knowledge;

- Promoting knowledge industries as well as strengthening their competitive potential;

- Brining ease for people, in terms of accessing desired information. In addition to this, it also aims to provide exceptional functionalities as well as ample opportunities for the generation of knowledge.

It has been assessed that the RKC caters to a number of knowledge and innovative institution, which are located along its main arterial road (Prince Turki AlAwal). KSU, RTV, KACST, ITCC, KAFD etc., can be considered as the most prominent institutions, which have implemented RKC. These institutions are also illustrated in figure 4.

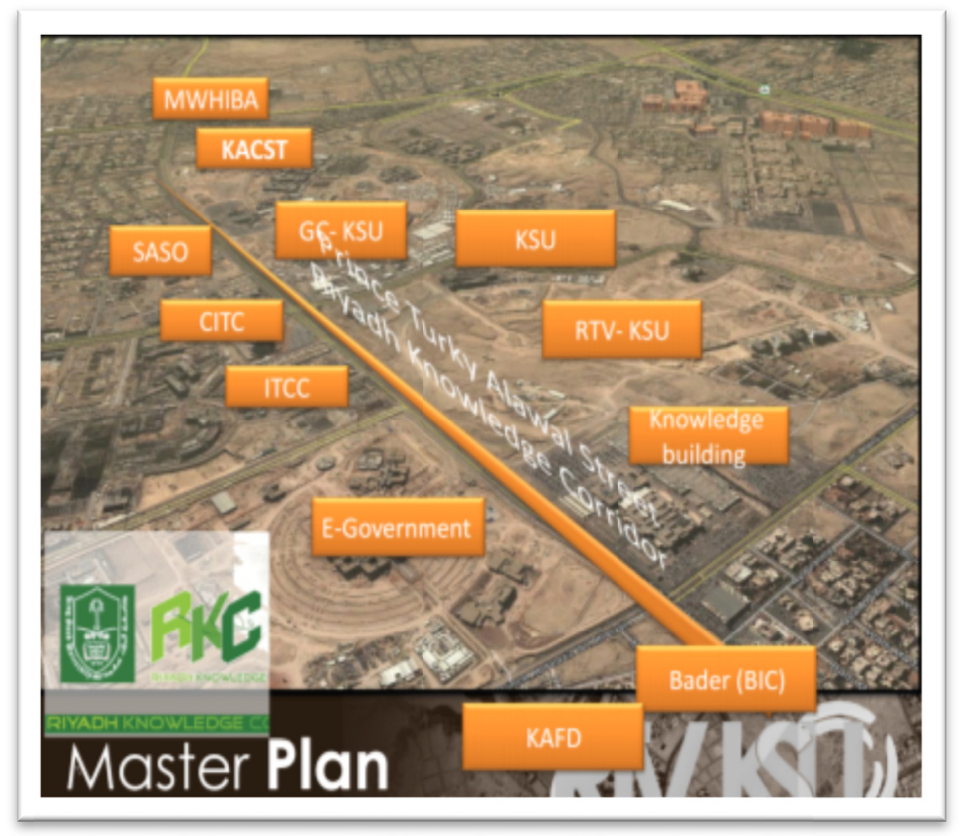

Figure 4. Knowledge and innovative institutions located along RKC 


\subsection{Brief Synopsis of Riyadh Techno Valley - Anchor for Smart Riyadh - NWD}

\subsubsection{RTV Strategy}

It has been established that Riyadh Technology Valley was developed, in order to acquire or attain the vision of Kingdom leadership, in order to come into the knowledge based economy. The term "knowledge based economy" can be understood as the environment which aims to convert knowledge into economic value through the transformation of technical developments into new services/products for economically investing into the market. Basically, such practices foster the trading of innovative and high-tech tools and equipments, which eventually results in the acquisition of higher revenues and economic benefits (Al-Filali \& Gallarotti, 2012, p. 19). Besides that RTV also aims to deliver a leading/outstanding smart campus and environment, in order to enhance research and development, efficient operation, maintenance, and service delivery. Moreover, it is also intended to ensure smart, dynamic, and cost-effective administration.

\subsubsection{Vision}

The vision of the program is to establish a leadership in the area of research and business development, as well as transference of technology.

\subsubsection{Mission}

The mission of RTV is to ensure the establishment of an eco-system, to attract research and business development centers towards forming a competitive and highly proficient knowledge based economy. One of the major intentions behind this act is to attain the notion of sustainable development.

\section{Method}

This research study has adopted qualitative secondary research method, in order to accumulate pertinent information, about given topic of research. One of the major objectives behind the adoption of this research method was to acquire up-to-date and reliable data about current trends of urban planning and design in Riyadh North-West district.

\section{Results and Discussion}

\subsection{The Strategic Plan for KSU}

For the period of the last three years, King Saud University has formulated the strategic plan 2030. Major objective behind this strategic plan was to direct KSU as a research university in Saudi Arabia by focusing more on applied research. It is expected by the university that the project will bridge information gaps between the university and the industry, and gain commercialized benefits from the academic research (Almobaireek \& Manolova, 2012, p. 4). It has been assessed that KSU is also moving progressively towards knowledge society in macro and micro scale in the kingdom by adopting innovations and entrepreneurial programs.

\subsection{The Kingdom's Development Plans towards a Knowledge Based Economy}

It has been established that the Kingdom has intended to establish "science and technology parks" at research centers and universities, in order to be consistent with the adherence of development plans. These programs are intended to develop a national basis of technology and science, which is able for renewal and innovation, along with innovative trend of formulating knowledge-based economy. In addition to this, such programs are also aimed at promoting and fostering joint research programs as well as co-financing among academic institutions and industrial sector. In order to accomplish all of these objectives, the King Saud University Council has accepted the establishment of Riyadh Techno Valley at KSU.

\subsection{Riyadh Techno Valley - 4th Generation Science Park}

The approach of brain circulation was devised in RTV in order to exchange new innovative business ideas and turn them into commercial realities. In addition to this, it is also aimed at exchanging the knowledge globally by using innovative and advanced technological tools such as internet, video conference, and satellite technologies, which are supported by reliable smart infrastructure in RTV. The diagrammatic illustration of the brain concept is also provided in figure 5 . 


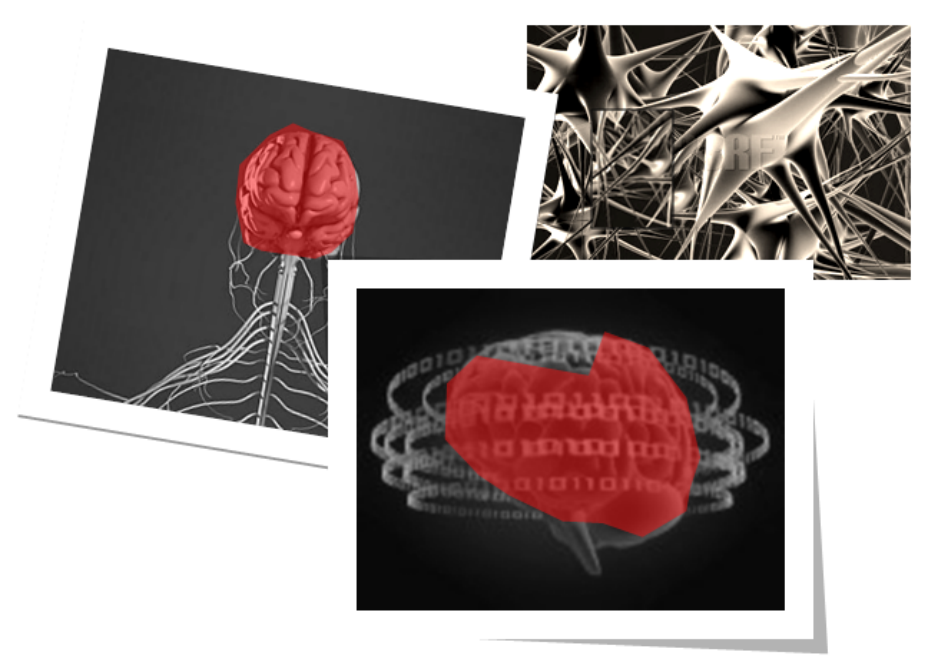

Figure 5. Brain circulation concept

\subsection{Research and Business Development (R\&BD)}

The main goal of the research and business development activities in RTV is to ensure the availability of optimal environment, in order to habitat and transfer innovative technologies. Additionally, it is also aimed at ensuring the attainment of such eco-systems, which are pertinent for the establishment and creation of contemporary technologies. All of these initiatives are taken by the governmental entities to achieve a knowledge based society.

\subsection{Technology and Effective Knowledge Management}

The utilization of such technologies, which provide feasible access to the managers and users, may play an inevitable role in enhancing and improving the entire process of knowledge management. Thereby, in order to ensure increased productivities at Science parks, the integration of smart software web-based application technologies will result in valuable outcomes (Al Rajhi, et al, 2012, p. 3). It is due to the fact that such efficient tools and technologies will simplify the process of searching and acquiring desired information. More so, it is also expected that the web-based application, in RTV, will also play an incredible role in advancing the overall performance, because of having the option of smart search. This smart search will be based on the storage of information, searching of user profile, and feasible retrieval of information. Furthermore, it will also foster efficient and effective communication practices amid different parties. It has been examined that the approach will play a significant role in maximizing the transference of technologies and sharing of valuable and beneficial knowledge.

The advanced approach utilizes the notion of GIS (geographic information system) within the internal infrastructure of the wireless technology's platform. It is intended to build up an interactive smart context-aware University GIS that improves different processes in RKC area and KSU campus. Some of the processes include dissemination, communication, and sharing of information. Major intention behind the utilization of such technologies is to develop information-insensitive eco-system, to support innovation, creativity, and knowledge in such multi-disciplinary environment (Almobaireek \& Manolova, 2012, p. 4).

\subsection{Effective Eco-System for Knowledge Base-Economy}

In order to launch and implement an eco-system for KBE at Science Parks, an appropriate and suitable model, which describes the role of each party, is needed to be developed. Moreover, such paradigms are also needed, which ensures structured and well-defined interaction among all parties. It is due to the fact that the innovation opportunities at the educational institutions will be increased with the right partnership and collaboration among government research institutions and private research companies, internationally and nationally.

This can be easily accomplished by the development of science park eco-systems, which possesses the focal role of synchronization and coordination between its stakeholders, university research sector, external private research, and its tenants. It is perceived that the initiatives, which are related with the innovation, will commendably impact the national economy. Precisely, it can be asserted that the national economy of the country will have highly beneficial impacts, once an effective knowledge management and eco-systems are deployed, as such steps will maximize the collaboration among all stakeholders; hence, result in the formulation of KBE (knowledge based economy). The proposed eco-system for RTV is diagrammatically represented in 
figure 6.

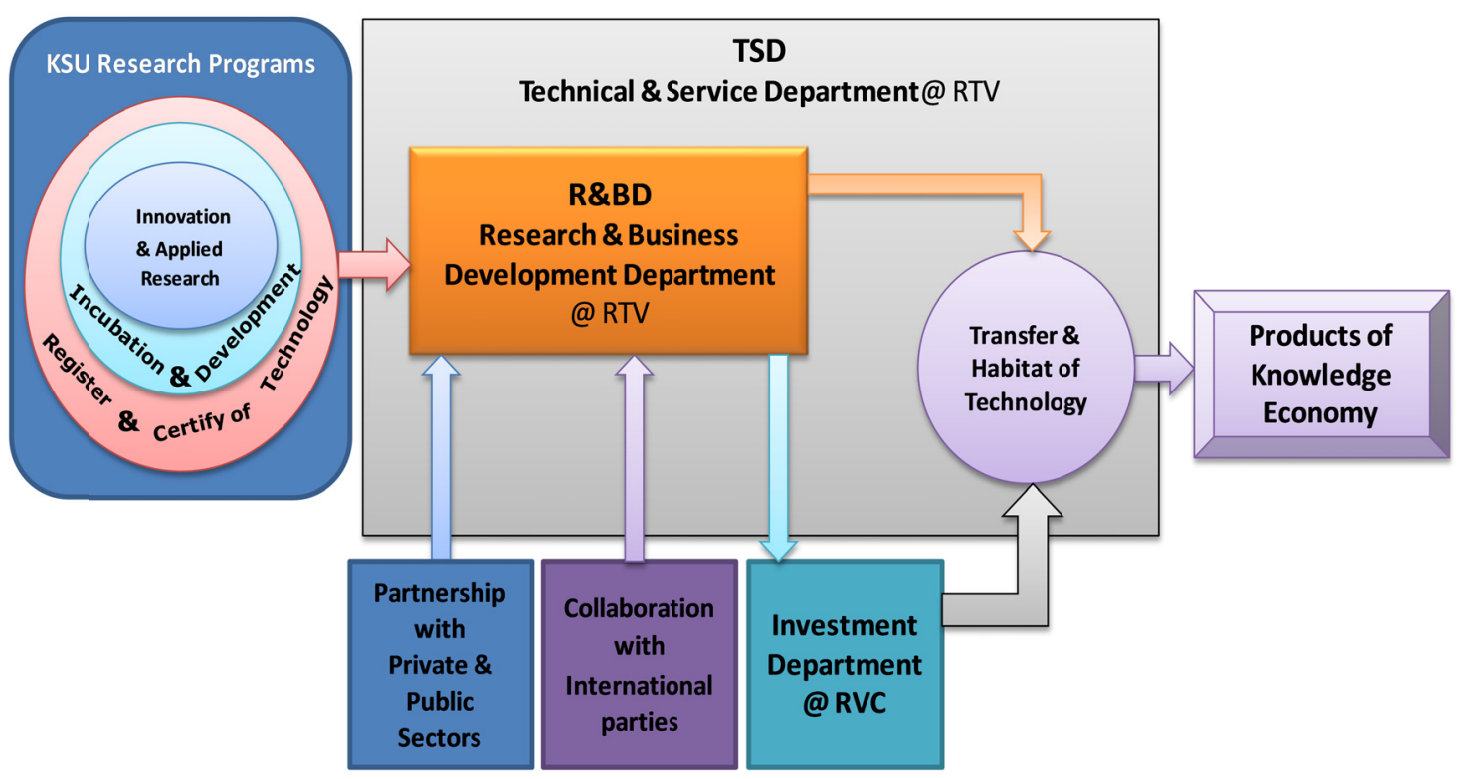

Figure 6. RTV - ECO system

\subsection{Smart Web Based Application}

Web-based database application can be considered as the greatest steps towards feasible and highly integrated retrieval and storage of information. Therefore, proper implementation of these applications enables its users to access or retrieve their desired information in a more efficient and secured manner, regardless of their geographical location. Utilization of web-based applications can help the organizations in improving their overall productivity, while minimizing certain delays and interruptions, which are usually occurred in information retrieval (Almobaireek \& Manolova, 2012, p. 4). Web-based application also supports real-time interaction of the employees with one another. In order to improve the overall performance of RTV, three web-based smart database applications have been presented. It is expected that these applications will enhance and improve several areas, including smart search, optimal knowledge sharing, storage and creation of knowledge, and productivity for processing projects (Wiseman, et al, 2014, p. 8). Improved interaction among all tenants and staff members of science parks and campus can also be considered as other greatest benefits, which are expected to be provided by web-based applications.

\subsection{RTV Master Plan}

Every single aspect of the RTV master plan is designed to ensure the acquisition of one or more than one objectives of RTV. Outlined below are the major planning guidelines of RTV, which will also help in recognizing the fact that how each guideline contributes to the overall Riyadh Techno Valley Vision. With the overall vision to create a science park that promotes an atmosphere of improved collaboration and innovation between industrial partners and knowledge based institutions, the RTV planning team has designed an infill development plan inside the KSU campus for RTV. It is important to notice that the total area, which is planned for RTV was $1,670,000 \mathrm{~m} 2$ within the KSU area which is 9,000,000 $\mathrm{m} 2$ (Al-Mosaind, 2014, p. 204). The pictorial representation of the plan is also incorporated figure 7. 


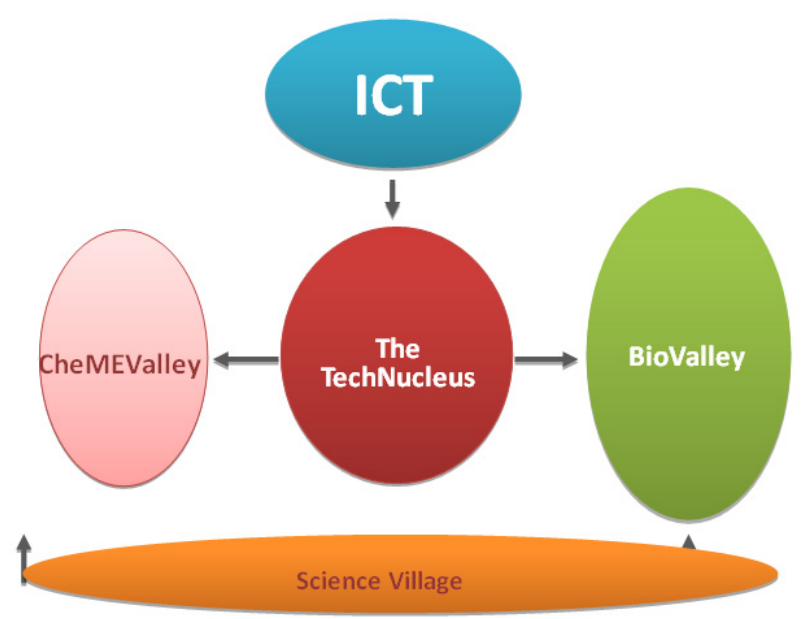

Figure 7. The technology clusters adopted in RTV Master Plan (SRI)

The proceeding mentioned major development clusters have been adopted to generate a vibrant mixed-use knowledge R\&BD center. The magnitude of each component was based on benchmarking of similar target developments, while keeping in view the current potential stakeholder requirements and KSU potentiality (Wiseman, et al, 2014, p. 8). The following are the technology clusters adopted in RTV master plan based on the feasibility study of Stanford Research Institute (SRI).

\subsection{Bio Cluster - Biotechnology}

This cluster is composed of research and business development (R\&BD), specifically in the areas of food science, environmental technology, as well as pharmacology.

\subsection{CheMCluster (Chemical Technology and Materials)}

This cluster is composed of research and business development (R\&BD), in the areas of energy, chemical materials, and petrochemical.

\subsection{ICT Cluster (Information and Communication Technologies)}

ICT cluster is composed of research and business development (R\&BD), the fields of information security, and information and communication technology.

\subsection{The Tech Nucleus Cluster (Catalytic Core and the Central Research Area)}

The catalytic heart of the science park, which resides the incubators, the office of support services of operations research, the centre for entrepreneurs, intellectual property, governmental centers and KSU centre for research and development, and laboratories to facilitate the local market. It is expected that each and every technological cluster will jointly incorporate a science village, which will serve as the educational and recreational mixed use core of the project (Al Rajhi, et al, 2012, p. 3). This zone will cater the workers in the science park, in addition to visitors from and outside the city of Riyadh. The technology clusters, which are adopted in RTV master plan (SRI), are presented in figure 7.

Central objective behind RTV is to highly populate the central district of research, business, education, entertainment, and lifestyle to act as catalyst to the development. It is assumed that the development will grow in layers from this catalyst; hence, result in radial expansion to the master plan. It has been suggested by the study of Stanford Research Institute Study that RTV must comprise four development clusters. Those clusters include tech nucleus, bio valley, chem Valley, and ICT Valley, while having the support of Science Village and mixed density residential clusters. Each development cluster is arranged along a tech/knowledge boulevard and is terminated by a Science Village. This corridor is important, as it is one of the prominent precedents to the environment of the park (Wiseman, et al, 2014, p. 8). The highly visible internal axis defines each cluster and is reflected in the surrounding densities. The building heights of the developments within the park is planned to accentuate the importance of this catalytic core. The master plan is demonstrated in figure 8. 


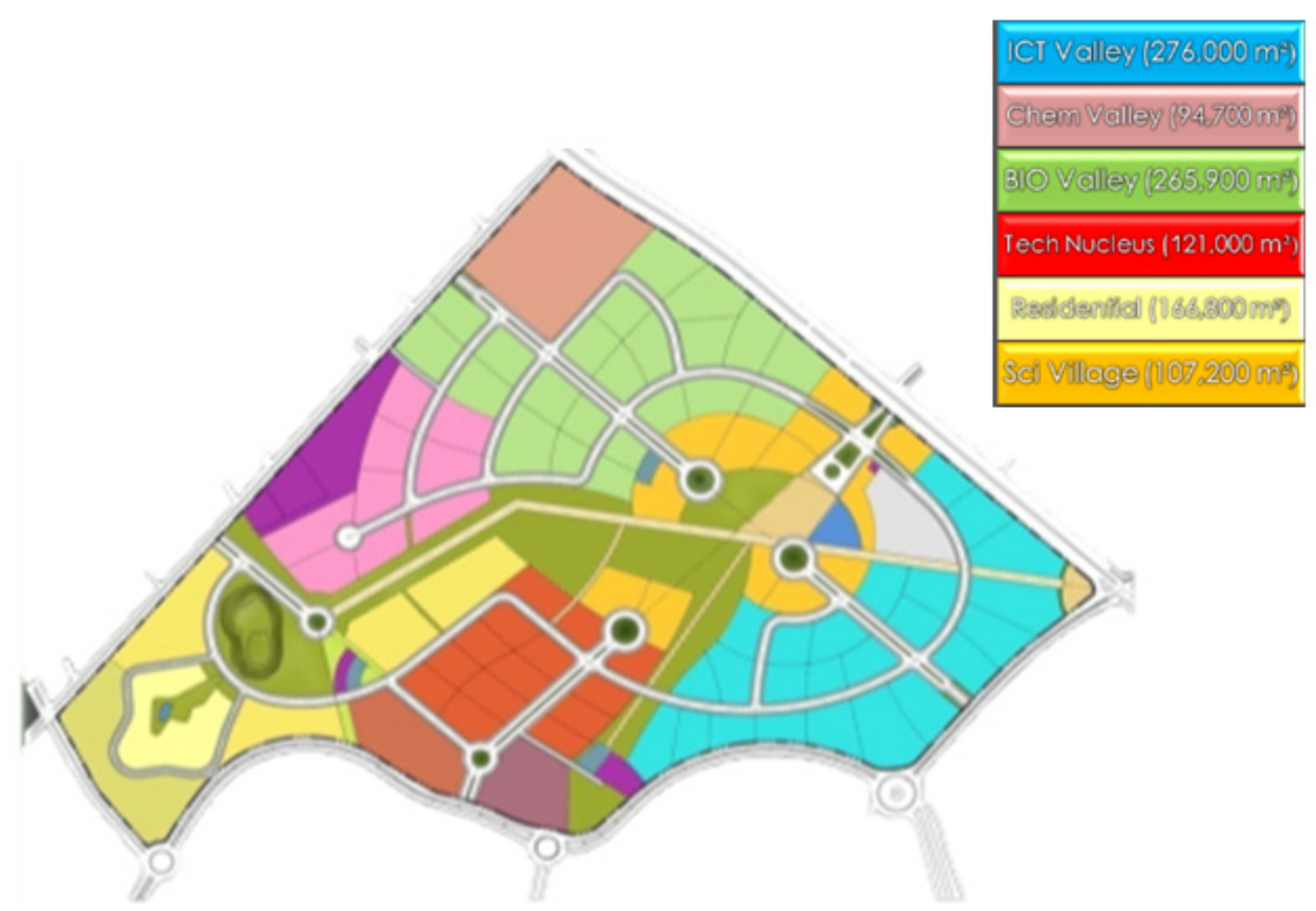

Figure 8. The RTV Master Plan done by Jurong International

\subsection{RTV Current Projects}

Some of the RTV projects include:

- $\quad$ Sustainable agriculture center;

- RTV smart infrastructure;

- $\quad$ Researchers Housing Towers;

- SABIC Plastics Applications Development Center;

- National Diabetes Center;

- $\quad$ RTV Main building (Innovation Tower);

- $\quad$ Prince Sultan Advanced Technology Institute;

- King Abdullah Institute for Nanotechnology.

Above mentioned projects are diagrammatically presented in figure 9 . 


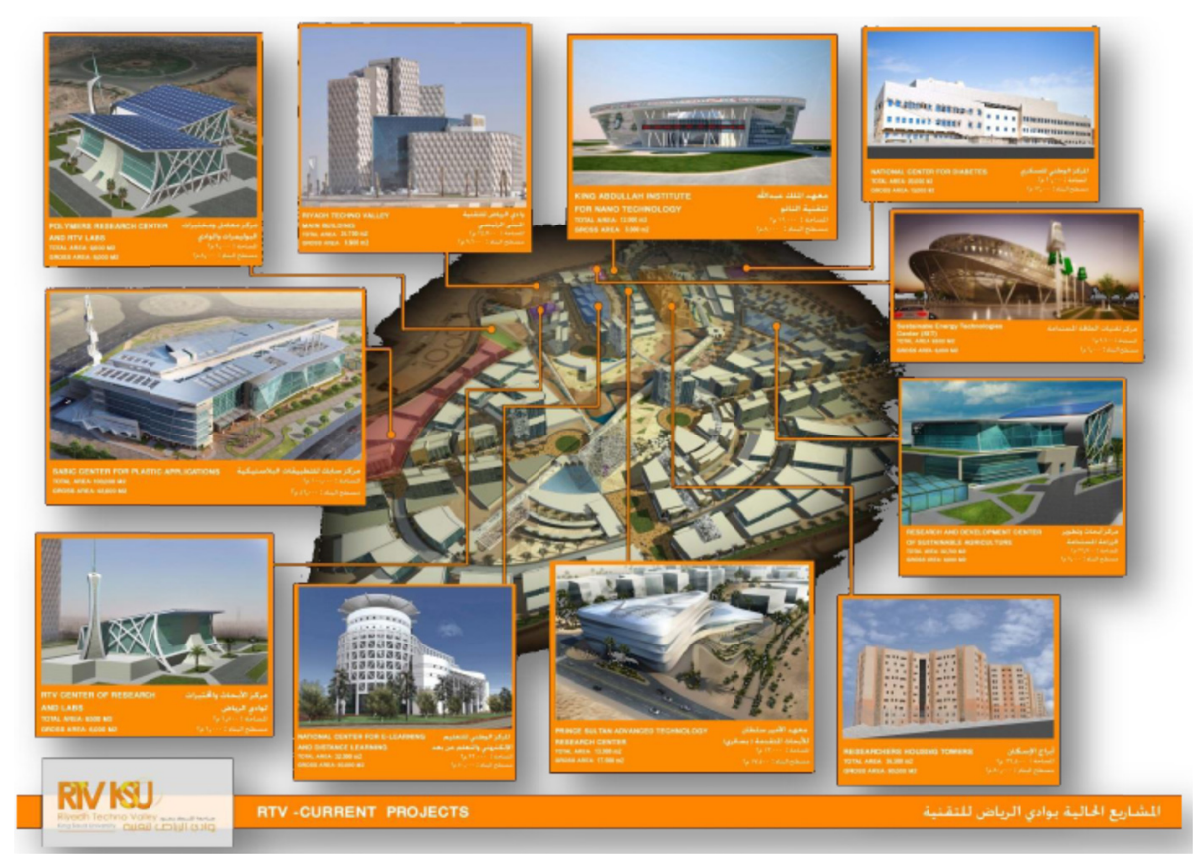

Figure 9. RTV current projects

\subsection{Riyadh Techno Valley Projects (Anchor to Smart Riyadh - NWD)}

3.14.1 Main building of Riyadh Techno Valley - Innovation Tower

Riyadh techno valley is situated in the land area of approximately $24.700 \mathrm{~m} 2$ and building area of about $9.600 \mathrm{~m} 2$ (Stingl, 2011, p. 2). It has been assessed that the building was mainly divided into two towers; the eastern tower, which is composed of ten floors and the West Tower. Moreover, the building is also found to be comprised of five floors. The two towers are connected together through the main lobby and linking bridges (Al Rajhi, et al, 2012, p. 3). The Valley adopted the application of open spaces and smart offices, for ease of re-division of office spaces, in order to keep pace with the expansion of the valley in the near future.

Half of the office area is allocated for meeting rooms, training rooms, and workshops. This infrastructure has been developed after considering the importance of communication, participation and debate in the research and development, innovation and technology transfer (Al-Mosaind, 2014, p. 204). The physical infrastructure of the buildings is represented in figure 10. In addition, the building of the Riyadh Technology Valley applies sustainability, green and smart building standards such as:

- $\quad$ Energy saving systems;

- Power saving lambs;

- $\quad$ Self-lighting control systems;

- Presence detector;

- Motion detector;

- $\quad$ Lighting intensity;

- Energy saving glass;

- Double Skin facade to protect the building from external climatic factors;

- Water conservation systems;

- Irrigation systems;

- Parking spaces are designed to have solar panels as a source for renewable energy for the RTV building. 

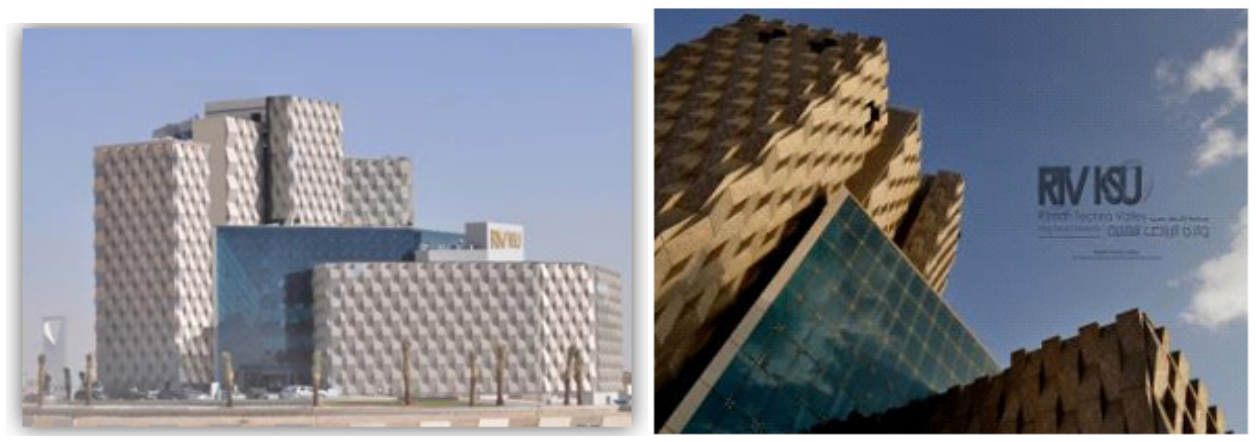

Figure 10. Main building of Riyadh Techno Valley

\subsection{King Abdullah Institute for NANO Technology}

King Abdullah institute for NANO technology is found to be located on the total land area of approximately $12.000 \mathrm{~m} 2$ and building area of the building is about $8.000 \mathrm{~m} 2$. The major concept behind the King Abdullah Institute for NANO technology building design was taken full benefit from the concept of NANO technology as well as its components, i.e., core and spinning of protons and electrons). The circular shape of the building design indicates the movement of protons and electrons around the nucleus, as presented in figure 11.
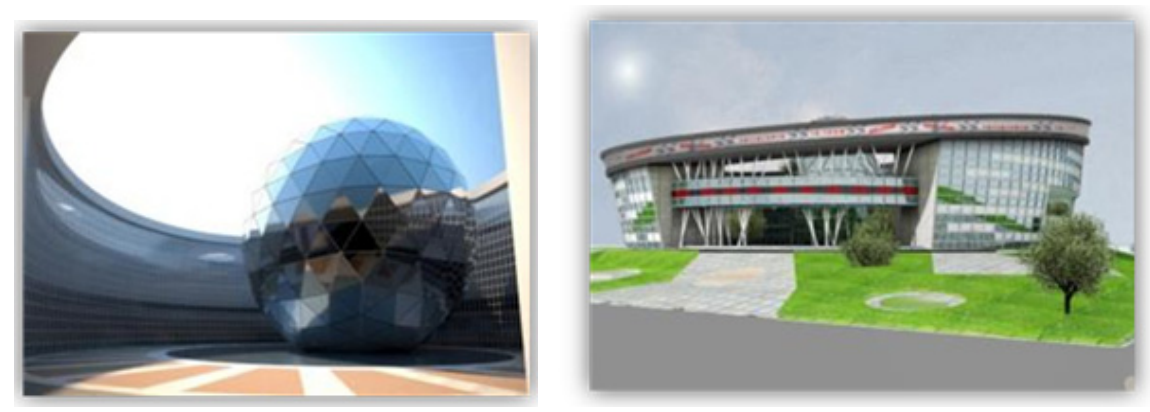

Figure 11. King Abdullah Institute for NANO Technology

A structured ball was put in the center that represents the main core, which functions as the main hall for conferences, meeting, and training rooms. The building considered the architectural design of the project by using state of the art architectural materials, in order to give a more sophisticated look and create a visual language that will reflect the intended design concept of the building (Gallarotti, 2013, p. 23). Therefore, it can be stated that the project is the architectural language and the idea is distinct architectural monument.

\subsection{Prince Sultan Advance Technology Institute}

Prince Sultan Advanced Technology Institute is situated on the land area of approximately $22.815 \mathrm{~m} 2$ and building area of $13.000 \mathrm{~m} 2$ (Shin, et al, 2012, p. 11). The building was designed along with having the aim of providing a profound and comprehensive knowledge of technical and scientific distinct that intends to regenerate and reutilize the private graduate programs and national capacity sessions that will conduct applied and basic research in certain areas, which aims to ensure national security. The pictorial representation of the institute is provided in figure 12 . 


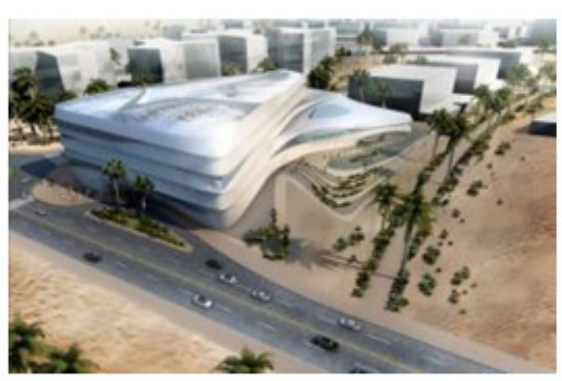

Figure 12. Prince Sultan Advance Technology Institute

\subsection{National Diabetes Center}

National diabetes center is established on the total land area of approximately $20000 \mathrm{~m} 2$.The mission of the national diabetes center is to provide advanced, effective, and organized health care facilities, along with high-quality services for the patients, suffering from diabetes. National diabetes center is equipped with high-tech tools and equipments, in order to regionally, nationally, and globally facilitate the patients (Salem, 2014, p. 29). The project consist of several departments, including clinical department, community services department, research department, clinics, 80 hypnosis rooms, in addition to the management and services. The infrastructure of this diabetes center is presented in figure 13 .
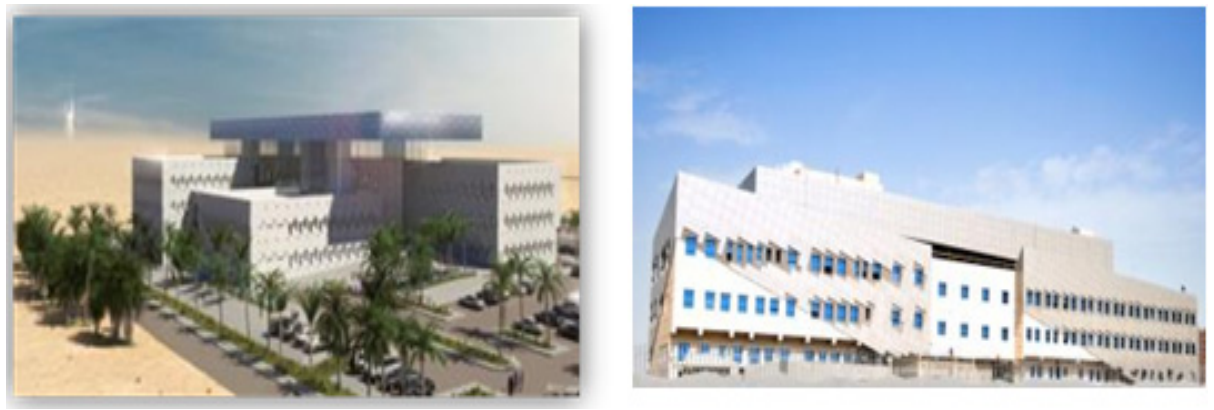

Figure 13. National Diabetes Center

\subsection{SABIC Plastic Applications Development Center}

SABIC plastic applications development center is established on a land area of $100.000 \mathrm{~m} 2$ as well as the building area of $42.000 \mathrm{~m} 2$. It is expected that the center will be equipped with the latest equipments and technologies. These technologies will provide the best available technology to keep the role of integrative with the remaining 15 SABIC technical centers inside and outside the Kingdom, which will qualifies the center to be one of the leading centers in building the knowledge-based economy (Gallarotti, 2013, p. 23). This center will also contribute with an active role in the process of resettlement of technology in the Kingdom by establishing a link between scientists and researchers in universities with the plastic industry manufacturers. The project is also considered LEED certified building because of the green building standards that had been applied in the project. The project is diagrammatically presented in figure 14 .
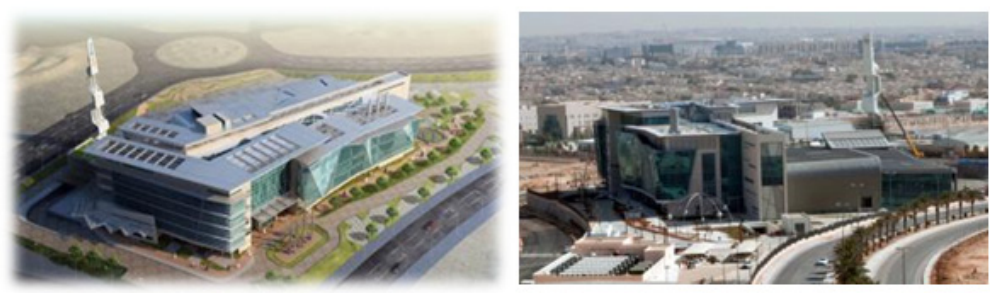

Figure 14. SABIC Plastic Applications Development Center 


\subsection{RTV - Science Village}

The RTV Science village is considered as the most efficient and dynamic center RTV, which aims at offering different intensity of activities, which plays a role of amalgamating element for more advanced and contemporary clusters (Salem, 2014, p. 29). It is observed that an optimal mix of uses within RTV is found to be considerably crucial for economic, cultural, as well as social vitality, in order to persuade effective and integrated communication and interaction activities. The science village is the visual junction of various district boulevards. It is directly accessed by the main landscaped RTV gateway along Prince Turki Alawal Street (Kbar, et al, 2012, p. 16). The project is a car free environment with an integrated people mover system that connects the science village to the entire RTV, as shown in figure 15 .
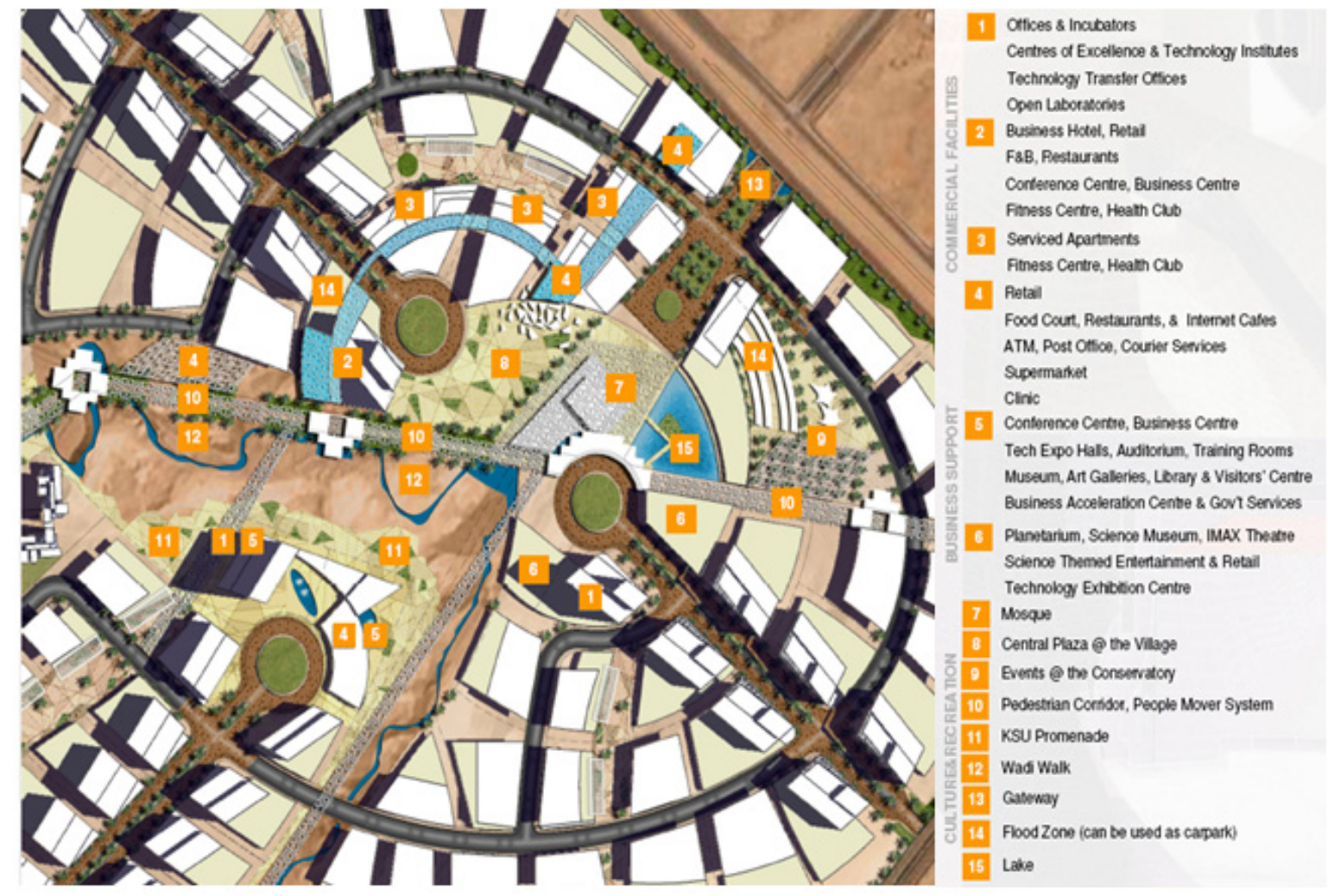

Figure 15. RTV Science Village

Science village is a lifestyle center with various scales of commercial, retail, food and beverage cafes, entertainment, health club, and cultural and lifestyle amenities. It also integrates science themed education facilities, like science and technology library, science museum, planetarium, business hotel, shopping plaza, and serviced apartments, which will support past working hours activities (Popovici, et al, 2013, p. 329). In the conjunction, it also includes meeting area where, public from different parts of the world and RTV scientist can exchange ideas, innovation, and knowledge to build a knowledge society.

\subsection{Smart Infrastructure and Services for RTV - Core Facilities of Smart City}

The project contains the state of the art main infrastructure (electricity, water, Irrigation, drainage, sewer, and telecom). The RTV has realized the importance of using smart technology, in order to increase the productivity of existing infrastructure; thereby, the project integrated a SMART service profile. It is expected that such services will increase the productivity not only for infrastructure, but also for people living and working in RTV. It is analyzed that the smart infrastructure is one of the finest applications of communication tools and technologies to infrastructure, in order to ensure more improved utilization of available resources (Khorsheed, et al, 2012, p. 11). The smart infrastructure can be utilized in various areas, including water, communications, life style, energy, and transport sectors.

The buildings and facilities are to be connected to a central command and control center through state-of-the-art communication network. Interconnectivity between buildings and command and control center shall utilize an 
optical fiber cabling system as a primary means of communications. Alternate and backup systems shall also utilize the Optical fiber cabling system (redundant and geographically diversified routes). Additionally, the systems will also utilize other means of communication such as, wired and wireless networks, in order to further enhance the features of availability, reliability, and security.

The optical fiber system is capable of supporting ultra-high speed communications (Terra bit) including TDM and DWDM networking and applications. The physical infrastructure as well as its core functions is presented in figure 16, figure 17, and figure 18. With the global trend in almost all technologies and applications utilizing, packet based communications (wired or wireless) all proposed systems shall be network based (or "IP based"). The system will provide a single integrated communication infrastructure for all systems and services or separate infrastructure for building management and safety/security applications (Kbar, et al, 2012, p. 16).

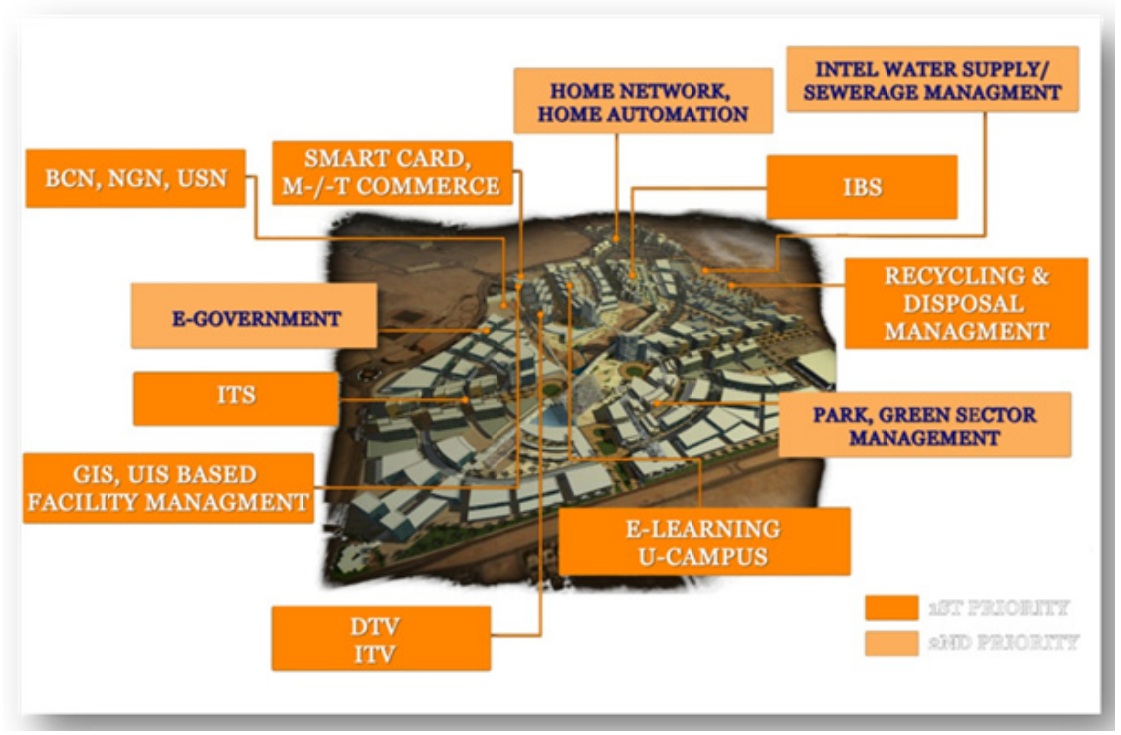

Figure 16. Core facilities of smart city
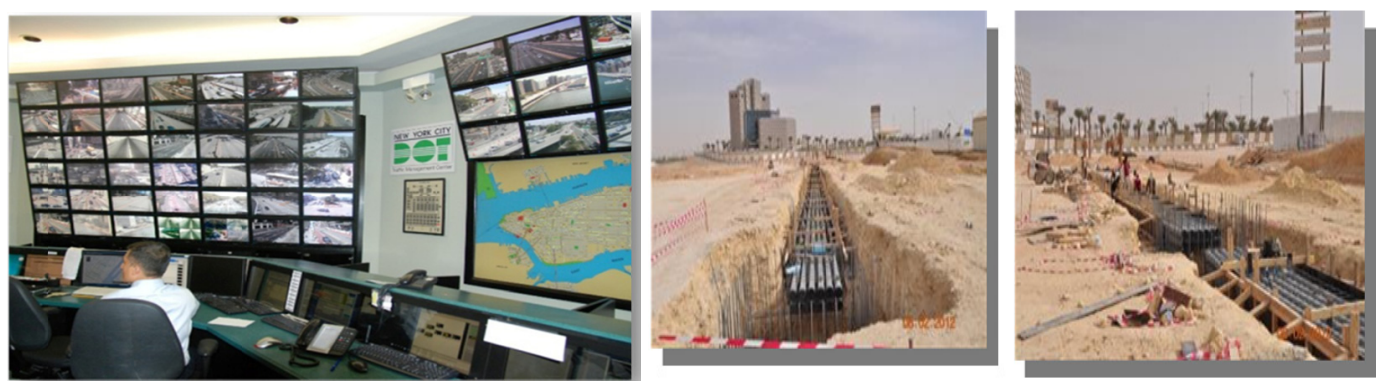

Figure 17. Core facilities of smart city

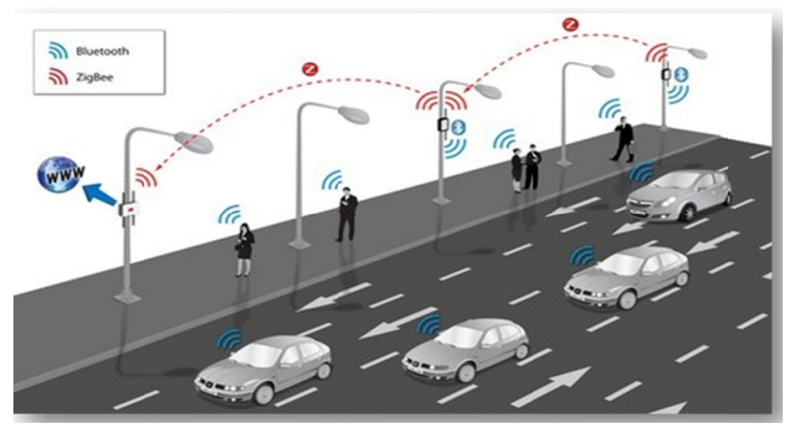

Figure 18. Communications infrastructure 
The system will include (as a minimum) and not limited to the following:

- Smart command and control center;

- Graphical information systems (and GIS based applications/services);

- Smart/intelligent building management system (BMS);

- Smart utilities monitoring and management system(s);

- Smart facilities monitoring and management system(s);

- Smart campus security monitoring and management system;

- Smart office/home security monitoring and management system;

- Smart road/traffic/parking monitoring and management system;

- Smart operations and maintenance services/system (including call center);

- Smart safety systems (fire/flood/gas/smoke detection and fighting, etc.);

- Smart public address and broadcast including warning systems;

- Smart access control and security system (including fences, gates, visitor, etc.);

- Smart surveillance and CCTV system including, recording and archival system;

- Smart asset management and inventory management system;

- Smart asset monitoring/tracking system;

- Main communication center (including services provider termination areas);

- Smart/modular main communication room (data center);

- Research high performance computing facility including visualization;

- Smart simulation and visualization facility with connectivity to LAB facility;

- Local Area Network (LAN), wireless LAN (WLAN) including outdoor network;

- Advanced data security and data leakage prevention solution;

- Intranet (branches, remote access, NREN, etc.);

- Extranet (companies, factories, etc.);

- Internet access

- WEB publishing and portal Services;

- Smart IP telephony including audio/video and IPT applications;

- Smart integrated unified messaging (voice mail, email, fax);

- Smart audio/video and Tele-presence solution (including multi-party);

- Smart collaboration systems/services/tools;

- Digital media and signage systems;

- Smart LAB and smart library;

- $\quad$ IPTV and VOD system;

- Community/social networking "Quad Play" services.

\section{Conclusion}

It has been analyzed from the acquired findings that Riyadh North-West district is swiftly drifting towards urban planning and design. It is due to the fact that various projects have been recently completed in the state and number of projects is in developing phase. After analyzing the current trends of urban planning in Riyadh North-West district, it has been established that smart services are likely to present a number of valuable benefits to RTV. It has been assessed that RTV and other developers can expect higher asset value and occupancy rate by Smart Community Service. In addition to this, it is also observed that RTV and other property managers can not only save operational cost, but also pursue additional revenue opportunities by Smart Community Service. Other benefit may include saving of operational cost through integration (energy saving cost of system operation and human resources). Moreover, faster and more efficient management with standardized facility management process can also be considered as one of the most prominent benefits of smart services to RTV. 
Smart services are also found to provide extensive benefits to the end-users, including businesses, home residences, retailers, and visitors. Some of the most prominent benefits include comfort and safe working environment, office automation and enterprise solutions, convenient and safe living environment, community social networking, advertisement throughout the whole RTV community, customer loyalty with smart card membership and mileage service, and convenient access to real-time community information customized for various purposes (business, social, shopping, and leisure).

\section{References}

Al Rajhi, A., Al Salamah, A., Malik, M., \& Wilson, R. (2012). Economic Development in Saudi Arabia. Routledge, $\quad p . \quad 3 . \quad$ Retrieved from https://books.google.com/books?hl=en\&lr=\&id=RbyUSv9zuEAC\&oi=fnd\&pg=PR3\&dq=Knowledge+Bas ed+Economy+in+saudi+arabia\&ots=zfu5niEBog\&sig=FCZA9ABn8zBMRmVXvOPVxDAwoOc\#v=onepa ge\&q=Knowledge $\% 20$ Based $\% 20$ Economy\%20in\%20saudi\%20arabia\&f=false

Al-Filali, I. Y., \& Gallarotti, G. M. (2012). Smart Development Saudi Arabia's Quest for a Knowledge Economy. International Studies, $p$. 19. Retrieved from http://isq.sagepub.com/content/49/1-2/47.short

Almobaireek, W. N., \& Manolova, T. S. (2012). Who wants to be an entrepreneur? Entrepreneurial intentions among Saudi university students. African Journal of Business Management, 4. Retrieved from http://www.academicjournals.org/article/article1380880710_Almobaireek\%20and\%20\%20Manolova.pdf

Al-Mosaind, M. (2014). Traffic Conditions in Emerging University Campuses: King Saud University, Riyadh, Saudi Arabia. Journal of Sustainable Development, 204. Retrieved from http://www.ccsenet.org/journal/index.php/jsd/article/view/41000

Gallarotti, G. M. (2013). Smart development: Saudi Arabia's quest for a knowledge economy. International Studies, $23.2 \quad$ Retrieved from http://wesscholar.wesleyan.edu/div2facpubs/128/?utm_source=wesscholar.wesleyan.edu\%2Fdiv2facpubs\% 2F128\&utm_medium=PDF\&utm_campaign=PDFCoverPages

Kbar, G., Aly, S., \& Alhanafi, B. (2012). Smart and Context Aware Search for University Campus (SCASUC), IEEE, $\quad$ p. $16 . \quad$ Retrieved $\mathrm{http} / /$ ieeexplore.ieee.org/xpl/login.jsp?tp=\&arnumber=6320141\&url=http\%3A\%2F\%2Fieeexplore.ieee.org \%2Fxpls\%2Fabs_all.jsp\%3Farnumber\%3D6320141

Khorsheed, M. S., Alhargan, A., \& Qasim, S. M. (2012). A Three-Tier service model for national ICT incubator in Saudi Arabia. In Proceedings of IEEE International Conference on Management and Service Science, $\mathrm{p}$. 11. Retrieved from http://www.researchgate.net/profile/Syed_Manzoor_Qasim/publication/231575193_A_Three-Tier_Service_ Model_for_National_ICT_Incubator_in_Saudi_Arabia/links/0fcfd50b8904759e62000000.pdf

Popovici, D., Desertot, M., Lecomte, S., \& Delot, T. (2013). A framework for mobile and context-aware applications applied to vehicular social networks. Social Network Analysis and Mining, 329. Retrieved from http://link.springer.com/article/10.1007/s13278-012-0073-9

Salem, M. I. (2014). The role of universities in building a knowledge-based economy in Saudi Arabia. International Business \& Economics Research Journal (IBER), 10. Retrieved from http://cluteinstitute.com/ojs/index.php/IBER/article/view/8771

Shin, J. C., Lee, S. J., \& Kim, Y. (2012). Knowledge-based innovation and collaboration: a triple-helix approach in Saudi Arabia. Scientometrics, $11 . \quad$ Retrieved from http://link.springer.com/article/10.1007/s11192-011-0518-3

Stingl, A. (2011). Knowledge-Based Economy. The Impacts of Technological Change, IR, p. 2. Retrieved from http://ir.nmu.org.ua/bitstream/handle/123456789/135536/ad072ae4ac7b7e6c11f93ddb0c7da0f2.pdf?sequen $\mathrm{ce}=1$ \&isAllowed $=\mathrm{y} \#$ page $=39$

Wiseman, A. W., Alromi, N. H., \& Alshumrani, S. A. (2014). Education for a knowledge society in arabian gulf countries, Emerald Group Publishing, p.8. Retrieved from, https://books.google.com/books?hl=en\&lr=\&id=v3QGAwAAQBAJ\&oi=fnd\&pg=PP1\&dq=Knowledge+Ba sed+Economy+in+saudi+arabia\&ots=vbWtcn9E8D\&sig=2iRV-pNpyES6oxy38rCPx_gv-7E\#v=onepage \&q $=$ Knowledge $\% 20$ Based $\% 20$ Economy $\% 20$ in $\% 20$ saudi $\% 20$ arabia $\&$ f=false

\section{Copyrights}

Copyright for this article is retained by the author(s), with first publication rights granted to the journal.

This is an open-access article distributed under the terms and conditions of the Creative Commons Attribution license (http://creativecommons.org/licenses/by/3.0/). 